\title{
Revealing the coexistence of differentiation and communication in an endemic hare, Lepus yarkandensis (Mammalia, Leporidae) using specific-length amplified fragment sequencing
}

\author{
Buweihailiqiemu Ababaikeri ${ }^{1,2+} \mathbb{0}$, Yucong Zhang ${ }^{1 \dagger}$, Huiying Dai ${ }^{1}$ and Wenjuan Shan ${ }^{1 *}$ (1)
}

\begin{abstract}
Background: The Yarkand hare (Lepus yarkandensis Günther, 1875) is endemic to oasis and desert areas around the Tarim Basin in the Xinjiang Uyghur Autonomous Region of northwest China; however, genome-wide information for this species remains limited. Moreover, the genetic variation, genetic structure, and phylogenetic relationships of Yarkand hare from the plateau mountain regions have not been reported. Thus, we used specific-length amplified fragment sequencing (SLAF-seq) technology to evaluate the genetic diversity of 76 Yarkand hares from seven geographic populations in the northern and southwestern parts of the Tarim Basin to investigate single-nucleotide polymorphism (SNP) marker-based population differentiation and evolutionary processes. Selective sweep analysis was conducted to identify genetic differences between populations.

Results: Using SLAF-seq, a total of 1,835,504 SNPs were initially obtained, of which 308,942 high-confidence SNPs were selected for further analysis. Yarkand hares exhibited a relatively high degree of genetic diversity at the SNP level. Based on pairwise $F_{\mathrm{ST}}$ estimates, the north and southwest groups showed a moderate level of genetic differentiation. Phylogenetic tree and population structure analyses demonstrated evident systematic phylogeographical structure patterns consistent with the geographical distribution of the hares. Hierarchical analysis of molecular variation further indicated that genetic variation was mainly observed within populations. Low to moderate genetic differentiation also occurred among populations despite a common genomic background, likely due to geographical barriers, genetic drift, and differential selection pressure of distinct environments. Nevertheless, the observed lineagemixing pattern, as indicated by the evolutionary tree, principal component analysis, population structure, and TreeMix analyses, suggests a certain degree of gene flow between the north and southwest groups. This may be related to the migration of hares to high-altitude water sources southwest of the basin during glacial climatic oscillations, as well as river re-diffusion and oasis restoration in the basin following the glacial period. We also identified candidate genes, and their associated gene ontology terms and pathways, related to the adaptation of Yarkand hares to different environmental habitats.
\end{abstract}

\footnotetext{
*Correspondence: swj@xju.edu.cn

${ }^{\dagger}$ Buweihailiqiemu Ababaikeri and Yucong Zhang have contributed

equally to this work

${ }^{1}$ Xinjiang Key Laboratory of Biological Resources and Genetic

Engineering, College of Life Science and Technology, Xinjiang University,

Urumqi 830046, China
}

Full list of author information is available at the end of the article original author(s) and the source, provide a link to the Creative Commons licence, and indicate if changes were made. The images or other third party material in this article are included in the article's Creative Commons licence, unless indicated otherwise in a credit line to the material. If material is not included in the article's Creative Commons licence and your intended use is not permitted by statutory regulation or exceeds the permitted use, you will need to obtain permission directly from the copyright holder. To view a copy of this licence, visit http://creativecommons.org/licenses/by/4.0/. The Creative Commons Public Domain Dedication waiver (http://creativeco mmons.org/publicdomain/zero/1.0/) applies to the data made available in this article, unless otherwise stated in a credit line to the data. 
Conclusions: The identified genome-wide SNPs, genetic diversity, and population structure of Yarkand hares expand our understanding of the genetic background of this endemic species and provide valuable insights into its environmental adaptation, allowing for further exploration of the underlying mechanisms.

Keywords: Yarkand hare, Specific-length amplified fragment sequencing (SLAF-seq), Genetic differentiation, Genetic diversity, Gene flow, Adaptation, Tarim Basin

\section{Background}

Identifying the levels of genetic variation within and between species or populations is an essential step in studying the influences of mutation, natural selection, and genetic drift [1]. Toward this end, it is often beneficial to understand genetic variation using population differentiation statistics such as the pairwise genetic differentiation estimate $\left(F_{\mathrm{ST}}\right)$ [2]. Population differentiation is a significant step toward speciation [3], potentially leading to the formation of new species or subspecies. The extent of genetic differentiation is shaped by various correlated and interacting factors, including population and migration sizes, breeding and mating systems, dispersal barriers, gene flow, social behaviors, reproductive strategies, and ecological selection structures [3]; among these factors, gene flow is the most important determining factor for genetic structure and differentiation in wild populations [4]. Furthermore, environmental factors may influence the colonization process, potentially affecting gene flow. Disruptions in dispersal processes, such as physical obstacles to migration, exchange of individuals among wildlife populations, and increased inbreeding within spatially isolated populations can reduce gene flow, leading to genetic differentiation $[5,6]$. To date, research investigating the factors influencing genetic differentiation and gene flow within a species has mainly focused on geographical or geological factors-such as the impact of Quaternary glacial fluctuations [7-9] and habitat fragmentation $[10,11]$-combined with anthropogenic activities, resulting in physical barriers that cause discontinuities in the distribution of a species [12].

The Yarkand hare species Lepus yarkandensis Günther, 1875 is distributed across marginal oases along the edges of rivers in the Tarim Basin, southern Xinjiang Uygur Autonomous Region (XUAR), northwest China [13]. The Yarkand hare relies on vegetation near streams that flow down from the melting water of surrounding snowy mountains. Its habitat includes poplar forests and brushwood along the river margins, and its distribution is restricted to riverine patches and scattered oases at altitudes between 900 and $1200 \mathrm{~m}$; these oases are physically isolated by the Taklamakan Desert [13, 14]. Kumar et al. [8] suggested that mountain habitats may also be suitable for Yarkand hare in the face of ongoing climate-induced range expansion. Indeed, our field investigations showed that the Yarkand hare is distributed in the mountain areas of Tashkurgan, Aketu, and Wuqia in the Pamir Plateau southwest of the Tarim Basin. The Yarkand hare shows strong adaptability to the extreme aridity, intense solar radiation, and intense heat of the Tarim Basin [15], which underwent desertification 5.3 million years ago (Mya) [16]. Over the past decade, wild populations of this species have drastically declined due to habitat fragmentation and deterioration of their distribution area resulting from aggravated human activities, including local economic development, oil exploitation, and illegal hunting. Consequently, the Yarkand hare is listed as a "vulnerable species" on the China Species Red List [17], and is now listed as "near threatened" by the International Union for Conservation of Nature [18].

Resolving the phylogenetic relationships between species and different populations within a species is a very important task in evolutionary biology and conservation genetics [6]. Previous studies exploring the genetic variation and phylogenetic relationships of Yarkand hare populations have focused on mitochondrial DNA (mtDNA) genes $[8,15,19-21]$, the male-specific Y-chromosomal sex-determining region (SRY) gene [21], and two nuclear DNA (nDNA) markers, namely, the mechano-growth factor $(M G F)$ and spectrin beta non-erythrocytic 1 (SPTBN1) genes [8]. Phylogenetic analysis of mtDNA sequences showed significant genetic differentiation among most Yarkand hare populations, highlighting low migration levels among populations inhabiting oases isolated by the Taklamakan Desert. This barrier proved to be effective against gene flow, suggesting the importance of habitat aridification, oasis development, and river runoff in the differentiation and evolutionary history of Yarkand hare populations $[19,20]$. However, these studies were limited by only analyzing mtDNA and nDNA fragment markers, and failed to include populations living in plateau mountain regions.

To the best of our knowledge, a systematic genomewide investigation of Yarkand hare genetic diversity, population structure, and phylogenetic relationships has not yet been conducted. Next-generation sequencing technology enables the identification of a large number of markers, including single-nucleotide polymorphisms (SNPs), across the genome in a cost-effective and highly reproducible manner. Given its high success rates, 
specificity, stability, low cost, and labeling efficiency, specific locus amplified fragment sequencing (SLAF-seq) can be directly used for chromosome-specific molecular marker development without the need to sequence the entire genome of a species. Indeed, SLAF-seq has been successfully used for gene identification [22] as well as in analyses of the genetic diversity and phylogenomics of several species [23-25]. Genomic data analysis provides detailed information on a population's genetic variations, historical dynamics, and adaptive characteristics, which can expand knowledge of genomes for non-model species, enabling comprehensive evaluation of evolutionary patterns and signatures that may benefit conservation efforts.

Species with a high level of population differentiation and a limited distribution range among populations may have reduced ability to cope with adverse environmental conditions [26, 27]. If a local population disappears or decreases, a large proportion of the total genetic variation may be lost [28]. These populations may then become more vulnerable to random genetic drift, which may contribute to population differentiation by randomly fixing alleles. Moreover, geographic isolation coupled with characteristics of a small population size and local adaptation leads to reduced genetic variation due to a decrease in gene flow [28]. Therefore, the extant populations of a species result from an often complex demographic history involving population splits, gene flow, and population size changes. Accurate data on the geographic boundaries of isolated populations, and the degree of genetic differentiation and individual exchange among these populations are thus vital for accurate species risk assessments and effective conservation planning [30]. Moreover, the detection of genomic differences can shed light on the genetic basis of adaptation to diverse environments and provide insights into functionally important genetic variants [31].

Therefore, to establish effective protection measures and sustainable management of Yarkand hare genetic resources in Xinjiang, China, we used the SLAF-seq approach to identify genome-wide SNP markers in Yarkand hare populations for the first time. Based on these data, we investigated the genetic diversity and differentiation, migration events, and evolutionary process of diversification of these populations. We also sought to identify possible genomic signatures of adaptation to various environmental conditions found across the range of this species by sampling individual hares from the northern and southwestern regions of Tarim Basin. Our specific research questions were as follows: (i) what is the genetic variation, differentiation, and phylogenetic relationship of Yarkand hare populations at the genome-wide level? (ii) What is the historical pattern of divergence and gene flow between populations? (iii) Are there genomic differences that may be related to environmental stress or their adaptation? These findings can help to provide a comprehensive view of the genetic structure and relationships among Yarkand hare populations and shed light on genomic regions that harbor genes related to adaptive traits in this species.

\section{Materials and methods}

\section{Sampling and DNA extraction}

Muscle or skin tissue samples were collected from a total of 76 Yarkand hares (L. yarkandensis) from seven geographic populations around the Tarim Basin from 2008 to 2018; 20 samples were obtained from Korla (KRL), 10 from Akesu (AKS), 5 from Alar (ALR), 12 from Tashkurgan (TX), 16 from Aketu (AKT), 10 from Kashgar (KS), and 3 from Wuqia (WQ) in XUAR, northwestern China. Some samples were obtained from roadkill or hares that died of natural causes, whereas others were obtained from specimens that had been confiscated from illegal poachers (provided by local forestry bureaus). The geographical details of the sampled populations are shown in Fig. 1. For ease of analysis, we divided these populations into two groups (north and southwest) based on their geographical location in the Tarim Basin. The north group included AKS, ALR, and KRL; these hare populations reside in the middle and lower reaches of rivers, where the climate is relatively hot and arid with an elevation not exceeding $1500 \mathrm{~m}$. The southwest group included the TX, AKT, KS, and WQ populations that live in an environment characterized by drought in the mountain areas of the Pamir Plateau along the upper reaches of Tarim River with an elevation higher than $1500 \mathrm{~m}$, even reaching up to $3000 \mathrm{~m}$ in some areas, including TX.

Muscle samples were preserved in sterile tubes with anhydrous alcohol at $-80{ }^{\circ} \mathrm{C}$ until total genomic DNA extraction using the standard phenol-chloroform extraction protocol [32]. Genomic DNA integrity was determined using $1.0 \%$ agarose gel electrophoresis with a lambda DNA standard, and the DNA purity and concentration were assessed using the Nanodrop ND-1000 spectral photometer (NanoDrop, Wilmington, DE, USA). A minimum of $30 \mathrm{ng} / \mu \mathrm{L}$ of DNA was used for sequencing.

\section{SLAF library preparation, sequencing, and quality control}

We used the domestic rabbit (Oryctolagus cuniculus) OryCun 2.0 genome [33], downloaded from the National Center for Biotechnology Information (NCBI; ftp:// ftp.ncbi.nlm.nih.gov/genomes/all/GCF/000/003/625/ GCF_000003625.3_OryCun2.0/) for a pre-experiment in silico simulation of the number of markers produced by multiple endonuclease combinations; the optimal restriction enzyme combination was predicted to be 


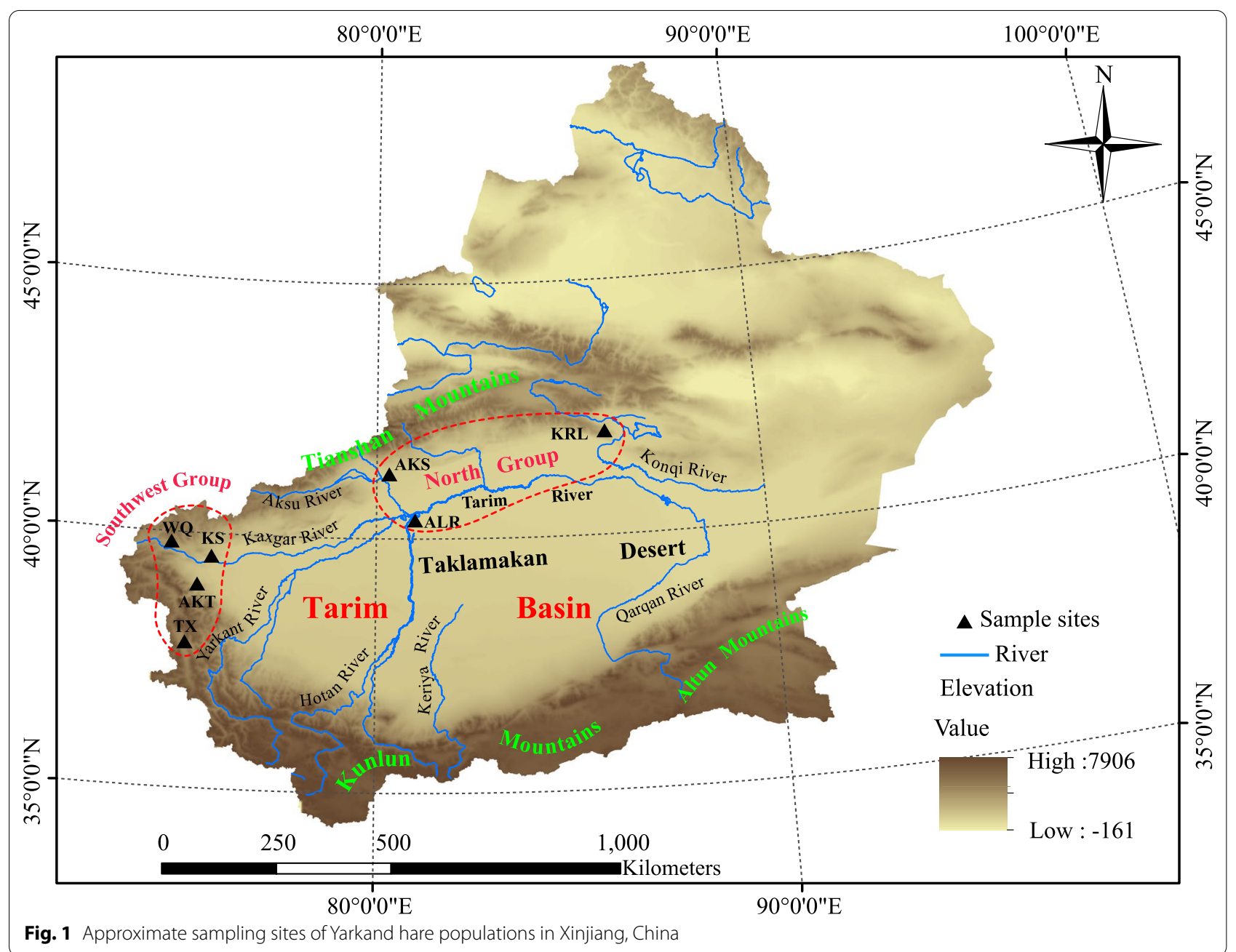

RsaI-EcoRV-HF ${ }^{\circledR}$. Based on the results of the pilot experiment, we constructed the SLAF library as per the methods reported by Sun et al. [34] and Zhang et al. [35], with slight modifications; DNA fragments 314-344 base pairs (bp) in size were selected as SLAFs and used for pairedend sequencing on an Illumina HiSeq 2500 system (Illumina, Inc., San Diego, CA, USA) at Beijing Biomarker Technologies Corporation (Beijing, China). Enzyme digestion efficiency, fragment insertion distribution, and alignment efficiency of the positive control (Oryza sativa ssp. japonica, http://rapdb.dna.affrc.go.jp/) were calculated using SOAP v2 software [36] to evaluate the reliability of the enzyme digestion experiment and the accuracy of library construction.

We conducted real-time monitoring for each cycle during sequencing to control the quality of the sequencing data. We also calculated the ratio of highquality reads according to raw read quality scores greater than Q30 (i.e., a quality score of 30, indicating that the probability of error is $0.1 \%$, and thus providing
99.9\% confidence) and the guanine-cytosine (GC) content as the two key quality indicators. Burrows-Wheeler Aligner (BWA) v0.7.5a-r405 [37] was used to map all sample reads onto the OryCun 2.0 genome sequence.

\section{Developing SLAF tags and SNP markers}

SLAF tags were mined according to the fragment size defined by the enzyme digestion scheme; SAMtools v0.1.18 [38] and GATK v3.3.2 [39] were used for SNP calling following evaluation of the sequencing depth and SLAF tag distributions on chromosomes. A locus was defined as a reliable SNP if it was simultaneously called by both packages. Filtering of high-quality SNPs was conducted according to the criteria of site information integrity $(\mathrm{INT}) \geq 0.5$ and minor allele frequency $(\mathrm{MAF}) \geq 0.05$ using Plink v1.07 software [40]. Finally, the selected high-quality SNPs were used for further analysis. 


\section{Genetic diversity analysis}

Summary statistics of genetic diversity, including nucleotide diversity $(\pi)$, observed heterozygosity $\left(H_{o}\right)$, expected heterozygosity $\left(H_{e}\right)$, and the polymorphism information content $(P I C)$, were calculated using Arlequin ver3.5 [41] and Power-Marker v3.25 [42].

\section{Phylogenetics, population structure, and principal component analysis}

Phylogenetic analyses were conducted using Bayesian inference (BI) and maximum-likelihood (ML) trees of an individual SNP matrix to clarify the phylogenetic relationships among geographic Yarkand hare populations from a genome-wide perspective; the rabbit $(\mathrm{O}$. $\mathrm{cunicu}$ lus) genome was used as the outgroup. BI phylogenetic analysis was performed using Exabayes ver1.4.1 [43]; 5 million generations were used for Bayesian Markov chain Monte Carlo (MCMC) iterations, with sampling every 500 generations. We performed ML analysis using IQ-TREE v1.6.1 [44], with 100 bootstraps to test the confidence of the branches. ModelFinder [45] was used to determine the best-fit base pair substitution model according to the Bayesian information criterion (BIC); the general time-reversible (GTR) model was selected as the optimal model for our datasets. The final BI tree was visualized and edited in FigTree ver1.4.2 (http://tree.bio. ed.ac.uk/software/figtree).

We estimated the pairwise population genetic fixation index $F_{\mathrm{ST}}$ and performed hierarchical analysis of molecular variation (AMOVA) using Arlequin ver3.5; the significance of variance components was determined via 10,000 random permutations. Principal component analysis (PCA) of all samples was conducted using EIGENSOFT ver7.2.1 [46], with the first three eigenvectors of total variation visualized. The population structure among the studied Yarkand hare populations was inferred using ADMIXTURE ver1.22 [47] with a Bayesian clustering method. Based on the same set of SNPs, the number of subgroups $(K)$ predicted from 1 to 10 and the number of ancestors was determined according to the position of the minimum value with an error rate obtained from cross-validation (CV) [48].

\section{Divergence time estimation and gene flow analysis}

A relaxed molecular clock model based on the ML method was used to estimate the divergence time using the MCMC Tree program in PAML ver4 [49]. Two points were calibrated to build the time tree, (1) the split of the genus Lepus occurring approximately 10.76 Mya $( \pm 0.86$ Mya), and (2) the divergence time of Yarkand hare estimated at approximately 0.64 Mya ( \pm 0.26 Mya), as established by previous work [50] that used time constraints from data published by Matthee et al. [51] and numerous fossil records were used to calibrate the evolutionary time of the genus Lepus and divergence of the Yarkand hare. The MCMC analysis was performed for a total of $1 \times 10^{6}$ generations with sampling every 50 generations; the first $5 \%$ of the trees were discarded as burn-ins. To estimate historical gene flow between populations, TreeMix ver1.12 [52] was used to deduce the pattern of population differentiation and mixing based on genome-wide allele frequencies in the branch graph, which best describes the relationship between populations and gene flow.

Selection sweep, gene annotation, and functional analysis We calculated the locus-specific divergence in allele frequencies between Yarkand hare populations and their different environment counterparts sampled in this study, based on the unbiased estimates of pairwise $F_{\mathrm{ST}}$ using VCFtools [53]. To detect genomic regions related to the selection of hare populations in different environments, we calculated all possible pairwise $\theta \pi$ values, which were $\log _{2}$-transformed $\left(\pi_{\text {control group }} / \pi_{\text {different environment group }}\right)$. Both $F_{\mathrm{ST}}$ and $\theta \pi$ values were quantified using a non-overlapping 10-kb sliding-window approach. Genes overlapping either partially or entirely within the 95\% threshold of the empirical distribution of the raw $F_{\mathrm{ST}^{-}}$values and $\log _{2}(\theta \pi$ ratio $)$ within regions were considered putative selection genes. Functional annotation for each candidate gene in these target regions was identified by comparing the gene set against the Kyoto Encyclopedia of Genes and Genomes (KEGG) database using the NCBI BLASTp tool [54]. Gene Ontology (GO) terms were obtained using Blast2GO [55] with default parameters. Metabolic pathways involving these genes were identified using the KEGG Automatic Annotation Server (KAAS) [56] with the bi-directional best-hit method. GO term and KEGG pathway enrichment analyses were then performed using the ClusterProfiler $\mathrm{R}$ package [57]. We applied a raw $p$-value cut-off of $<0.05$ to identify significantly enriched $\mathrm{GO}$ terms and KEGG pathways.

\section{Results \\ High-throughput SLAF sequencing}

DNA sequences of 314-344 bp were selected as SLAFs for the Yarkand hare, and approximately 215, 273 SLAF tags were projected to be produced. Sequencing results for the positive control indicated that enzyme digestion efficiency, comparisons, and fragment selection evaluations were normal and reliable.

High-throughput sequencing of the SLAF library yielded 373.19 $\mathrm{Mb}$ raw reads, with an average of $4,910,380$ reads per individual. After strict filtration, $372.14 \mathrm{Mb}$ of high-quality clean data, with an average of 4,896,576 reads per individual, were obtained (Additional file 1: Table S1). Furthermore, the average Q20 and Q30 
was $98.12 \%$ and $95.43 \%$, respectively (Additional file 1: Table S1), indicating the reliability of the tested sequence results. The average mapping rate of our samples to the reference genome (OryCun 2.0) was $95.16 \%$ and the average GC content was 41.29\% (Additional file 1: Table S1).

\section{Development of SLAF tags and SNP marker selection}

A total of 3,527,350 SLAF tags were generated from the 76 specimens, with an average sequencing depth of $13.95 \times$ (Additional file 1: Table S1), which were well distributed across all chromosomes (Additional file 2: Fig. S1). A total of $1,835,504$ SNPs were identified across all samples following alignment to the reference genome, and the SNP integrity ranged from $31.38 \%$ to $47.38 \%$, with an average of $39.84 \%$ (Additional file 1: Table S1). To reduce the sequencing errors, baseline differences were removed and accuracy was assessed, resulting in 308,942 highly consistent and confident SNP markers $(\mathrm{MAF} \geq 0.05$ and $\mathrm{INT} \geq 0.5)$ that were selected for further analysis.

\section{Genetic diversity and differentiation}

Nucleotide diversity $(\pi)$ ranged from 0.0524 (KRL population) to 0.0845 (TX population) across the seven geographic populations of Yarkand hare, with an average of
0.0655 per population (Table 1 ). The average $H_{e}, H_{o}$, and PIC values of all populations were $0.3130,0.2582$, and 0.2543 , respectively, with the highest and lowest values observed in the WQ and KRL populations, respectively (Table 1). In total, excluding the AKT population, the genetic diversity indices of the southwest group were higher than those of the north group (Table 1).

Estimated $F_{\mathrm{ST}}$ values (Table 2) among all pairs of populations were generally low to moderate, ranging from 0.0161 to 0.1297 , indicating the presence of genetic structuring among these Yarkand hare populations. Moderate differentiation was noted between the southwest KS and WQ populations and all north populations, whereas only minimal genetic differentiation was found between the southwest AKT and TX populations and all north populations. Notably, the differentiation degree $\left(F_{\mathrm{ST}}=0.0689\right.$ 0.1297 ) between TX and the other southwest populations (KS, WQ, and AKT) was higher than that between TX and the north group populations $\left(F_{\mathrm{ST}}=0.0472-0.0633\right)$ (Table 2), even though the TX population is geographically located in the southwest region of the Tarim Basin.

Genetic differences among the seven geographical populations were further examined using AMOVA, suggesting that the genetic differences predominantly originated from within-population differences $(90.66 \%, p<0.01)$;

Table 1 Summary statistics of the genetic diversity of Yarkand hares analyzed in this study

\begin{tabular}{lllllll}
\hline Group & Population (abbreviation) & $\begin{array}{l}\text { Number of } \\
\text { samples (N) }\end{array}$ & $\begin{array}{l}\text { Nucleotide } \\
\text { diversity }(\boldsymbol{\pi})\end{array}$ & $\begin{array}{l}\text { Expected } \\
\text { heterozygosity } \\
(\boldsymbol{H e})\end{array}$ & $\begin{array}{l}\text { Observed } \\
\text { heterozygosity } \\
(\boldsymbol{H o})\end{array}$ & $\begin{array}{l}\text { Polymorphism } \\
\text { information content } \\
(\boldsymbol{P I C})\end{array}$ \\
\hline North group & Akesu (AKS) & 10 & 0.0551 & 0.3060 & 0.2380 & 0.2493 \\
& Alar (ALR) & 5 & 0.0592 & 0.3376 & 0.3143 & 0.2733 \\
& Korla (KRL) & 20 & 0.0524 & 0.2659 & 0.2030 & 0.2186 \\
Southwest group & Taxkorgan (TX) & 12 & 0.0845 & 0.3030 & 0.2451 & 0.2464 \\
& Aketu (AKT) & 16 & 0.0543 & 0.2744 & 0.2207 & 0.2266 \\
& Kashgar (KS) & 10 & 0.0835 & 0.3194 & 0.2294 & 0.2595 \\
Mean & Wuqia (WQ) & 3 & 0.0697 & 0.3846 & 0.3566 & 0.3065 \\
\hline
\end{tabular}

Samples were divided into two groups based on geographic location on the Tarim Basin

Table 2 Pairwise $F_{S T}$ values among different geographic populations of Yarkand hares

\begin{tabular}{|c|c|c|c|c|c|c|c|}
\hline Population & AKS & ALR & KRL & $T X$ & AKT & KS & WQ \\
\hline \multicolumn{8}{|l|}{ AKS } \\
\hline ALR & 0.0501 & & & & & & \\
\hline KRL & 0.0161 & 0.0392 & & & & & \\
\hline TX & 0.0570 & 0.0633 & 0.0472 & & & & \\
\hline AKT & 0.0382 & 0.0520 & 0.0283 & 0.0689 & & & \\
\hline KS & 0.1029 & 0.1052 & 0.0918 & 0.1297 & 0.0448 & & \\
\hline WQ & 0.0932 & 0.1027 & 0.0832 & 0.1223 & 0.0470 & 0.0608 & \\
\hline
\end{tabular}


only $9.34 \%$ of the variability was partitioned among populations $(p<0.01)$ (Table 3$)$. When pooling individuals into two to three groups based on their geographic distribution in the Tarim Basin (according to the $F_{\mathrm{ST}}$ results, the southwest TX population was included in the north group or separated as its own group), the genetic variation within populations was much higher than that among groups or populations.

\section{Phylogenetic analysis and population genetic structure}

As the topological structure of the BI and ML evolutionary trees was consistent (Additional file 3: Fig. S2), we combined the trees. The Yarkand hares analyzed in this study were divided into two main clusters with high confidence (Fig. 2a). The first branch was predominantly located at the root of the tree, which comprised individuals from the southwest group (WQ, AKT, and KS populations) and two individuals from the KRL population in the north group. The other branch included samples from the north KRL, AKS, and ALR populations; all TX samples; and three individuals from the KS population in the southwest group. Notably, all samples from the TX population in the southwest group clustered with samples from the north group; together, these samples formed the second-largest branch, which included three smaller branches. However, the TX population formed a small branch, fully distinct from the first main cluster comprising the other southwest group samples (Fig. 2a).

Genetic differentiation among the populations was also evident in the PCA (Fig. 2b). Population relationships in the ordination space were largely consistent with the geographical distribution of samples, which was in agreement with the phylogenetic tree (Fig. 2a). Specifically, KS samples were scattered on the left of the PCA plot, whereas almost all other samples were relatively concentrated on the right of the plot (Fig. 2b); the TX population clustered near the north group samples to the far right.

Assessment of the population structure using ADMIXTURE indicated two main ancestral subgroups based on the lowest cross-validation errors at a $K$ value of 2 (Additional file 4: Fig. S3). Four KS individuals from the southwest group formed an ancestral cluster when $K=2$.
The majority of the north group samples, all TX samples, and three KS individuals formed another ancestral cluster; the remaining samples from both the southwest and north groups showed different degrees of mixed ancestry (Fig. 2c). However, when $K=3$, the TX population was further separated, showing a distinct ancestry, whereas all ALR samples and one KRL sample from the north group were mixed among three ancestral clusters (Fig. 2c).

\section{Divergence time estimation and gene exchange analysis}

The MCMC algorithm with a general time-reversible model base pair substitution model was used to construct a Yarkand hare differentiation time-merging tree (Fig. 3a). The Yarkand hare's most recent common ancestor, Lepus timidus, occurred approximately 0.86 Mya [95\% highest posterior density (HPD): approximately 0.73-0.94 Mya]. The Yarkand hare population differentiation events predominantly occurred approximately $0.81-$ $0.32 \mathrm{Mya}$, exhibiting a general south-to-north trend, with the southwest KS population showing the earliest differentiation (0.81 Mya).

We inferred Yarkand hare migration events using TreeMix to further reveal the population structure with ADMIXTURE (Fig. 3b). Consistently, the tree topology indicated that all of the southwest populations, excluding TX, clustered into a single branch, whereas the north group populations and the southwest TX population clustered into a separate branch. A large number of migration events were identified among these Yarkand hare populations. Two migrations were detected with strong migratory signals, including one event that began from the north AKS population to the southwest AKT population (migration weight 0.455 ) and one that began from an ancestor common to both the southwest and north groups toward the southwest TX population (migration weight 0.450 ).

\section{Screening for selective sweeps in the Yarkand hare populations}

Based on the ADMIXTURE and PCA results, as well as the climate and geographical features of the sampling

Table 3 AMOVA among the Yarkand hare populations

\begin{tabular}{|c|c|c|c|c|c|c|}
\hline \multirow[t]{2}{*}{ Groups } & \multicolumn{3}{|c|}{ Differentiation coefficient } & \multicolumn{3}{|c|}{ Percentage of variation (\%) } \\
\hline & $F_{\mathrm{CT}}$ & $F_{\mathrm{SC}}$ & $F_{\mathrm{ST}}$ & Between groups & $\begin{array}{l}\text { Between } \\
\text { populations }\end{array}$ & Within population \\
\hline [AKS; ALR; KRL; TX; AKT; KS; WQ] & - & - & $0.093^{* *}$ & - & $9.34^{* *}$ & 90.66 \\
\hline [AKS; ALR; KRL;TX] [AKT; KS; WQ] & $0.064^{* *}$ & $0.058^{* *}$ & $0.118^{* *}$ & $6.39^{* *}$ & $5.41^{* *}$ & $88.20^{* *}$ \\
\hline [AKS; ALR; KRL] [TX] [AKT; KS; WQ] & $0.070^{*}$ & $0.048^{* *}$ & $0.115^{* *}$ & $6.98 *$ & $4.49^{* *}$ & $88.54^{* *}$ \\
\hline
\end{tabular}

$F_{\mathrm{CT}}$ represents genetic differences among groups; $F_{\mathrm{SC}}$ represents genetic differences among populations within groups; $F_{\mathrm{ST}}$ represents genetic differences among populations; ${ }^{*} 0.010<p<0.050,{ }^{* *} 0.010<p<0.001$ 

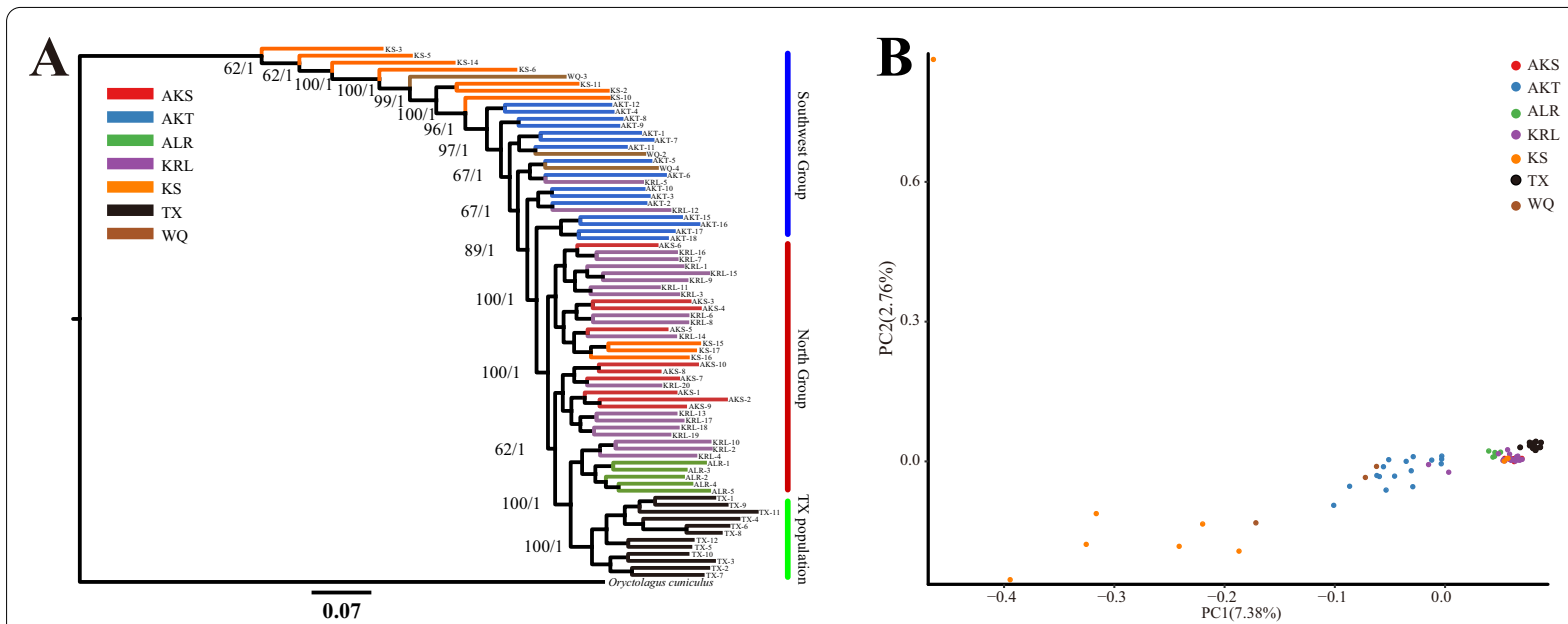

C

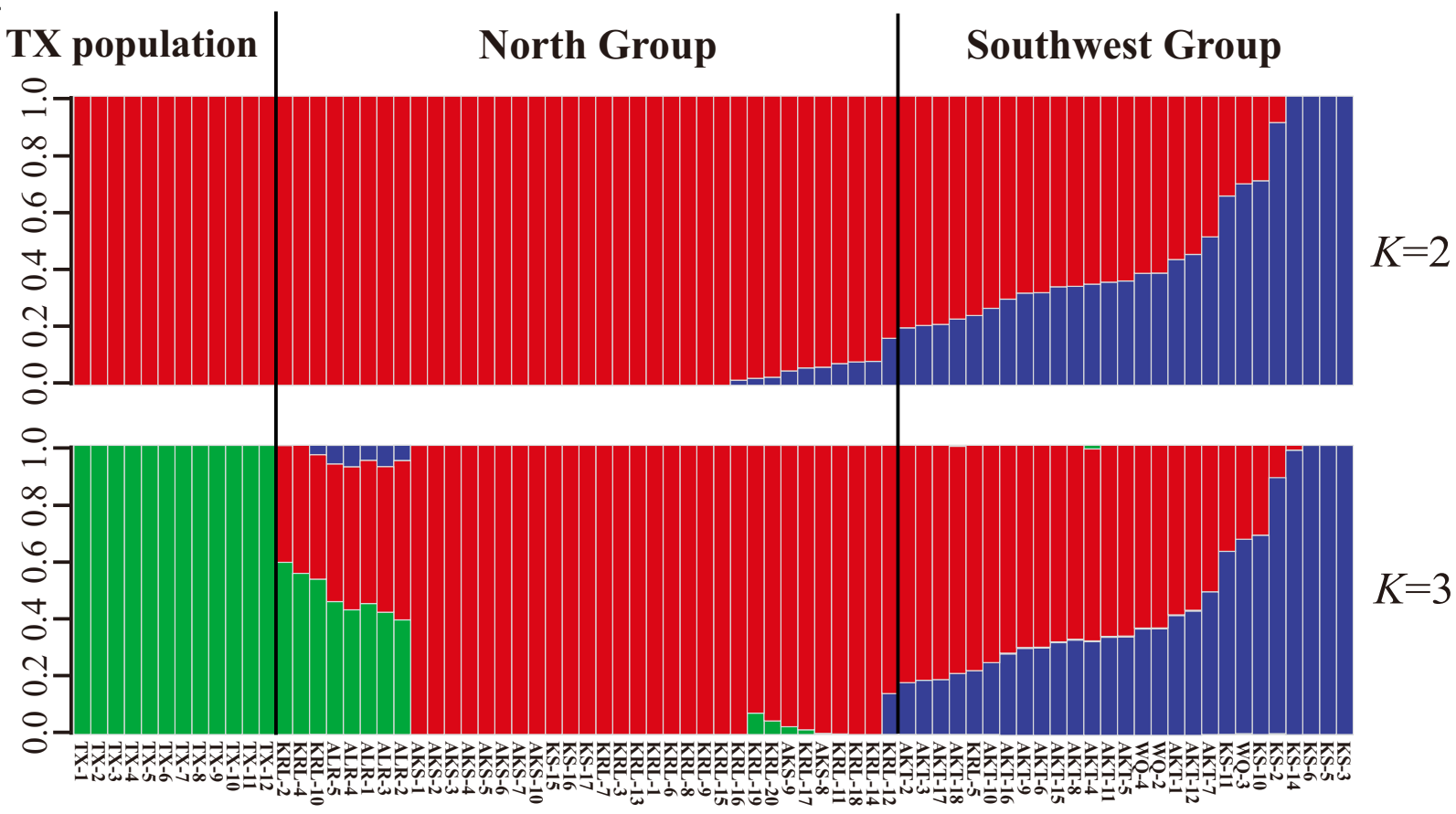

Fig. 2 Phylogenetic analyses and population structure of Yarkand hare based on high-quality SNP datasets. a Phylogenetic tree with Oryctolagus cuniculus as the outgroup. $\mathbf{b}$ Scatterplot of the principal components for the seven geographic populations. $\mathbf{c}$ Genetic structure of 76 Yarkand hares. The number of ancestral populations $(K=2-3)$ is indicated

sites, we combined the north group populations (AKS, ALR, and KRL), represented by an arid, hot, and plain environment, into a single gene pool. We combined the southwest group (AKT and WQ), represented by an arid and medium-altitude (elevation between 1500 and $2500 \mathrm{~m}$ ) environment, into another gene pool. The TX population in the cold, arid, and high-altitude (elevation $>3000 \mathrm{~m}$ ) environment was considered as a separate group. As the KS population includes samples collected from both plain and medium-altitude $(>1500 \mathrm{~m})$ areas, we excluded this population from this part of the analysis. Selection sweep analyses were performed by calculating the $5 \%$ highest $F_{\mathrm{ST}}$ values and the $\theta \pi$ ratio cut-off values between the following group pairs: north group vs. southwest group, north group vs. TX, and southwest group vs. TX, which identified 30, 17, and 15 candidate genes, respectively (Additional file 5: Table S2 and Fig. 4). The functions of these genes-based on their enriched 

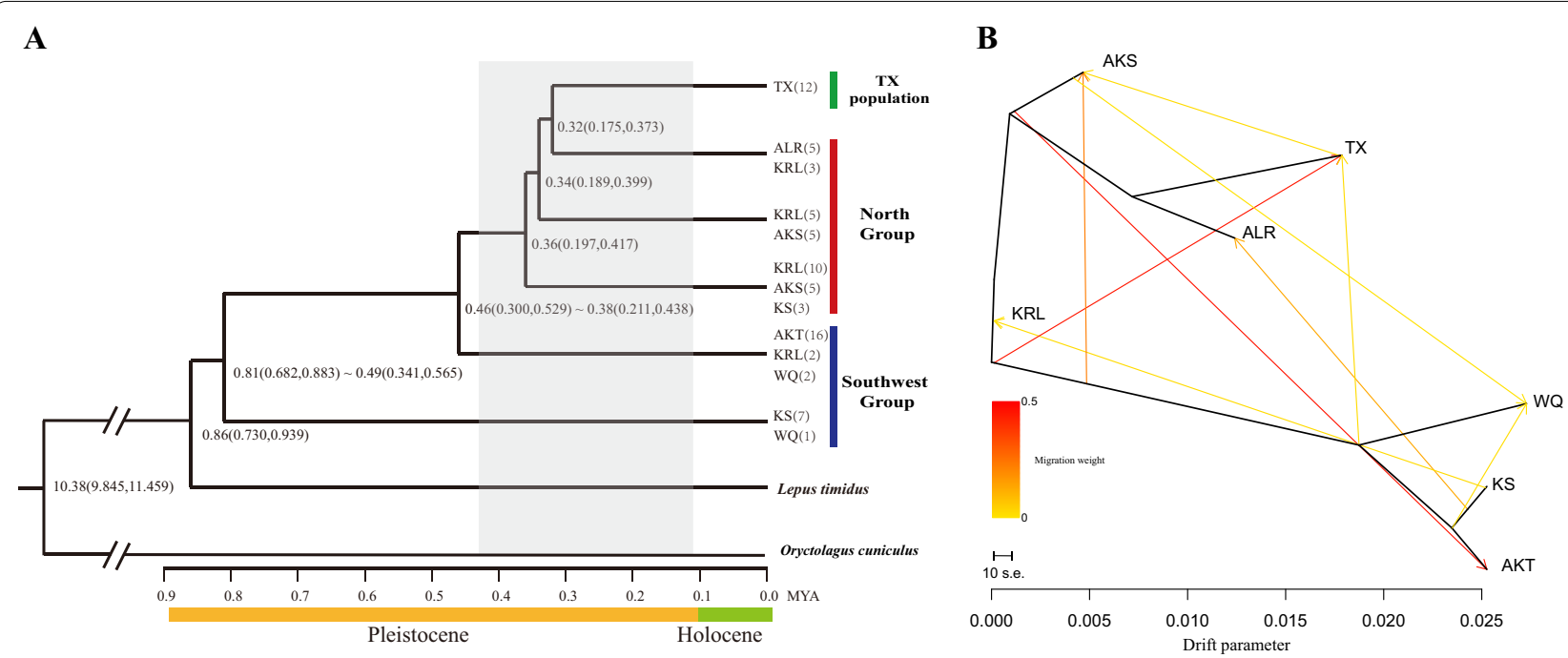

Fig. 3 Divergence time and migration events among Yarkand hare populations. a Time scale of major divergence in the Yarkand hare populations. The colors of the bars at the branch tips correspond to the group colors in Fig. 2. b Inferred Yarkand hare phylogenetic tree with mixture events among populations. Arrows indicate migration events and are colored according to their migration weight. Horizontal branch lengths are proportional to the amount of genetic drift estimated among populations

functional GO categories and KEGG pathways-were mainly related to energy metabolism, cell survival and proliferation, water reabsorption, response to stimulus, and oxidative stress (Additional file 6: Table S3, Additional file 7: Table S4, and Additional file 8: Table S5).

\section{Discussion}

In Xinjiang, Yarkand hares inhabit both natural and artificial oases, and are also found along the major river edges in the Tarim Basin encircling the Taklamakan Desert, which is the second largest sand sea on Earth. In this first genome-wide study of the Yarkand hare using SLAF-seq, we found low to moderate, yet significant, genetic differentiation between populations despite relatively long geographic distances. Interestingly, some genetic exchange among populations was also detected in the phylogenetic tree, PCA, and ADMIXTURE analyses. Indeed, the TreeMix analysis estimated a certain degree of gene flow among geographically separated populations. These results indicate that both genetic differentiation and gene exchange co-occur among the populations of this species. In addition, some selection signatures corresponding to genomic regions potentially under selection were identified in association with environmental differences, indicating a certain degree of local adaptation.

\section{Genetic diversity analyses using Yarkand hare whole-genome SNPs}

Genetic diversity in both endangered and common species may play an important role in ecosystem integrity and sustainability, and is also essential for conserving a population's evolutionary potential to adapt to changing environments [6]. In this study, a set of genome-wide SNP markers was employed for genetic variation analyses. In contrast to previous studies reporting that domestic animals, such as rabbits [58,59], dogs [60], pigs [61], and horses [62] are less genetically diverse than their wild counterparts, the average genetic diversity indices $\pi$ (0.0655), PIC (0.2543), and $H_{o}(0.2582)$ of the Yarkand hare were slightly lower than those of the domestic rabbit (O. cuniculus) [63]. However, this finding is in line with the hypothesis that among mammalian species, rabbits have relatively high levels of nucleotide diversity, which is likely related to their greater long-term effective population size compared with those of other sequenced mammalian species $[59,64]$. In addition, the $H_{e}$ was higher than the $H_{o}$ in all Yarkand hare populations sampled in this study. A similar heterozygosity pattern was also observed in Gazella subgutturosa populations sampled in Xinjiang [65], which may indicate limited genetic exchange among populations possibly caused by natural physical barriers and habitat fragmentation.

The nucleotide diversity of Yarkand hares $(\pi=0.0655)$ in our study based on whole-genome SNP sequencing was much higher than that previously reported for two mtDNA genes $\left(\pi_{C y t b}=0.008 \pm 0.004\right.$ and $\pi_{D}$. loop $=0.031 \pm 0.015)[15,20]$, the male-specific $S R Y$ gene $(\pi=0.000123)$ [21], and two nDNA fragment markers $\left(\pi_{M G F}=0.018\right.$ and $\left.\pi_{S P T B N 1}=0.003\right)$ [8], confirming that genome-wide SNPs obtained using SLAF-seq can detect 


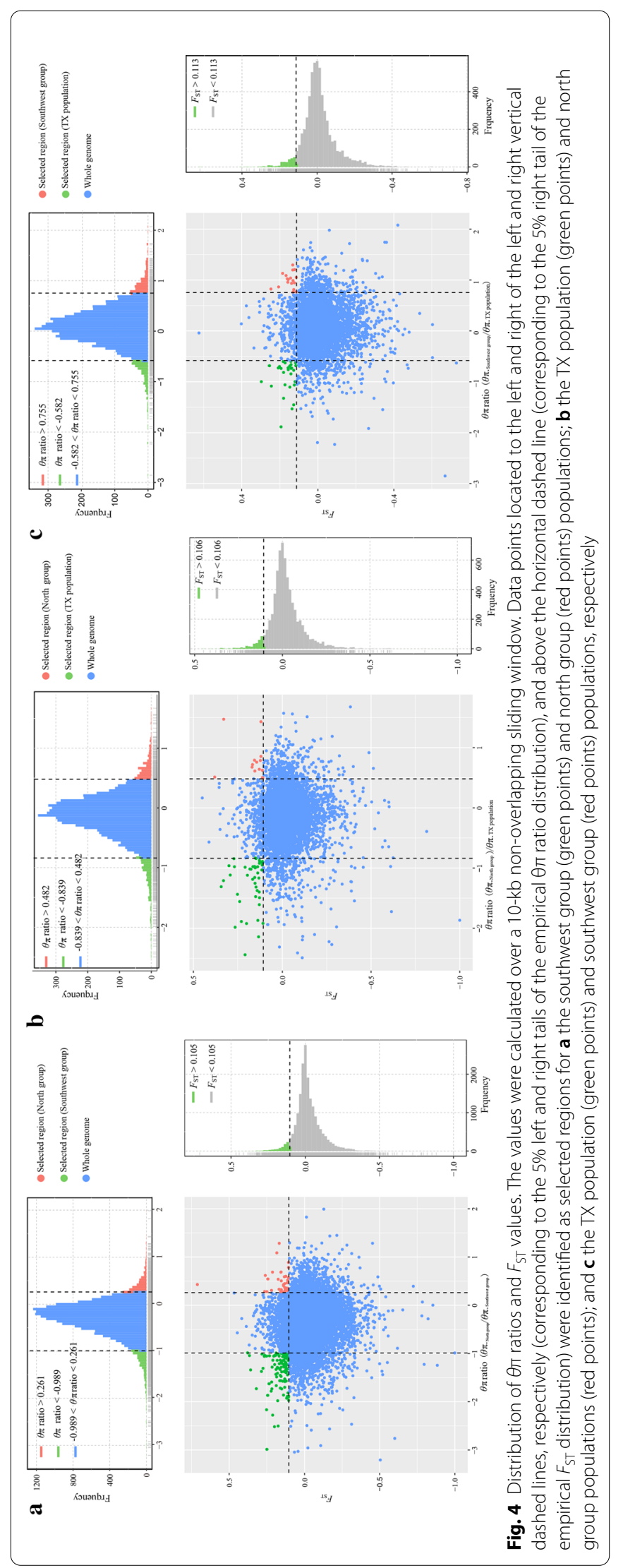


abundant variations. Furthermore, the genetic diversity of the southwest group (excluding AKT) was relatively higher than that of the north group, indicating a certain degree of inbreeding in northern populations. One possible explanation for this pattern is that the southwest Tarim Basin-the origin of basin rivers-was a glacial refugium for the Yarkand hare during Quaternary climatic fluctuations [15], providing a suitable environment for maintaining the relatively high genetic diversity of this species. In contrast, rivers in the northern and eastern parts of the basin dried out during the glacial period; thus, flora and fauna depending on oases produced by meltwater either died or retreated to the southwest [15]. Furthermore, as industry and transportation in the southwest Tarim Basin are less developed than those in the north, hare habitats in the southwest are less disturbed by human interference, thereby facilitating frequent gene exchange to ultimately maintain higher genetic variation. In addition, the northern and eastern Tarim Basin ecosystems are more susceptible to habitat loss and degradation than those in the southwest [15]. Habitat degradation caused by fragmentation may have influenced the genetic diversity of the north group populations through reduced gene flow and increased inbreeding. Among them, the KRL population distributed in the northernmost part of the Tarim Basin exhibited the lowest genetic variation level, which may be explained-to some degree-by the geographical isolation and disturbed natural habitats resulting from frequent anthropogenic activities such as increased transportation and expansion of agricultural land.

\section{Co-occurrence of genetic differentiation and gene flow in the Yarkand hare}

Our phylogenetic tree and PCA results showed that when the seven populations were divided into the north (AKS, ALR, and KRL) and southwest (TX, AKT, KS, and WQ) groups or when TX samples from plateau mountain areas were considered as a distinct group (TX population), a clear Yarkand hare phylogeographical distribution pattern was observed. This structure was also supported by the pairwise $F_{\mathrm{ST}}$ values among populations (Table 2), which indicated moderate genetic differentiation between the southwest KS and WQ populations, and the north group populations, as well as the TX population. Genetic differences among populations in Yarkand hare were further identified via ADMIXTURE with two main distinct lineages ( $K=2$, Fig. 2c) and according to the AMOVA showing significant $p$-values for $F_{\mathrm{ST}}$ (Table 3). This finding is consistent with that of previous studies showing mitochondrial fragment-based genetic and geographic differentiation between the southwest and northeast Yarkand hare populations [15, 19, 20,66].
This genetic differentiation pattern among populations also corresponds with evidence regarding morphological differences between hares in the southwestern and northern regions of the Tarim Basin [67]. We speculate that existing geographical barriers physically isolated populations from dispersion and exchange, leading to genetic differentiation. Specifically, the Yarkand hare populations have likely undergone genetic differentiation as a result of irreversible habitat fragmentation [8] and vegetation cover destruction due to anthropogenic actions that have directly changed the course of Tarim River [68] as well as the oasis landscape and vegetative cover over the past 200 years [69]. Regional aridification, shifting sands, and winds have destroyed vast oasis areas in the southern regions of the desert $[69,70]$, potentially affecting genetic admixture between geographically isolated populations. Reportedly, populations with reduced size in isolated habitats may have differentiated via selection and genetic drift during glacial cycles [71]. Indeed, genetic drift may partly contribute to the differentiation of Yarkand hare [8]. We also found a substantial increase in drift in the other three southwest group populations (i.e., KS, WQ, and AKT) compared with the TX population, as revealed by the TREEMIX results (Fig. 3). Genetic drift may also account for the higher degree of genetic differentiation found between TX and the other southwest populations compared with that found between TX and the north populations. Given that the TX population is geographically located in the southwest of the Tarim Basin, the identified population structure might also reflect the different environmental conditions across the Tarim Basin (i.e., temperature and altitude), which may impose different types of selective pressure on Yarkand hares, as observed for other species such as Diptychus maculates [24] and urchins [72] according to genome-wide SNPbased analysis. Future studies should include historical demographic events such as range expansions and population bottlenecks in such analyses, which may shape allele frequency patterns between populations, to explore these hypotheses based on genome-wide SNP markers.

Environmental changes during glacial periods may also merge previously isolated populations. Repeated signatures of migration and mixing are evident in the history of Yarkand hare populations [8, 19]. Despite clear population differentiation and significant pairwise $F_{\mathrm{ST}}$ values among populations, our phylogenetic analyses also revealed a high degree of lineage admixture (Table 3, Figs. 2 and 3). Population differentiation and mixing may be revealed by assessing migration events, including geographical migration and evolutionary processes, each of which may be marked by genetic evidence [73]. In the present study, gene flow and divergence estimates further confirmed that extensive gene exchange may 
have occurred among Yarkand hare populations during ancient geological periods. According to geological evidence, previous Yarkand hare habitats were more continuous than current habitats [20]. Thus, migration events may have contributed to the southwest group's AKT, $\mathrm{WQ}$, and KS (three individuals) remaining in the north group lineage in large proportions. Similarly, the north group ALR population and some KRL individuals were clustered in the TX population lineage $(K=3)$. Notably, one of the three KS population migration events involved migration to the KRL population (Fig. 3b), which may be a reasonable explanation for the KS and KRL populations clustering together in our phylogenetic analysis (Fig. 2).

Two main explanations can be proposed for this relatively extensive gene flow between geographically isolated populations. The first possibility is related to the intrinsic features of the hare. Despite the harsh living conditions of the Tarim Basin, the Yarkand hare as a small mammal has strong adaptability to environmental changes. Furthermore, large effective population sizes, rapid locomotion, and extensive and long-distance dispersal capability can all promote gene exchange between populations along the oases, villages, farmlands, and fixed and semi-fixed sand dunes on the edge and surrounding the Gobi Desert. Moreover, gene exchange may be facilitated through the "green channels" that have been constructed for wildlife on roads and highways. Similarly, green corridors and bridges over rivers may also facilitate gene exchange. The second possibility is that gene flow has been maintained owing to repeated migration events toward glacial shelters under climate variations. A certain degree of gene exchange between the southwest populations in high-altitude areas near the Tarim Basin and the north populations at lower elevations in the basin's hinterland may be related to refugia migration in the southwestern regions of the Tarim Basin during the Quaternary glacial period [15]. In general, areas with high biodiversity such as those maintaining stable habitats and accumulating genetic diversity during significant environmental changes are considered to provide biological refugia to species $[71,74]$. Considering the overall high nucleotide diversity of the southwest group (Table 1), its root position in the phylogenetic tree (Fig. 2a), and the direction of desert expansion and shifting sand dunes, migration was likely concentrated from the northeast to the southwest. Moreover, the southwestern regions of the Tarim Basin, as the origin of rivers in the basin, may have acted as a glacial refugia for the Yarkand hare, a finding that is consistent with previous mitochondrial marker-based results [15]. Following the retreat of glaciers during the Penultimate Glacial Period (0.30-0.13 Mya) [75], species in glacial refugia likely recolonized the northern and eastern regions of the basin $[15,76]$. Furthermore, with increasing glacial meltwater, rivers reoccupied their courses and oases were restored in the center of the basin due to the relatively warm and humid climate near the end of the Late Pleistocene (0.13-0.07 Mya) $[75,77]$. During recolonization, rivers may play a significant role in forming oases and green oasis corridors, along which hares could disperse, likely promoting extensive gene flow between the northern and southern populations [20]. Similar recolonization patterns were found in many European and North American species during ice ages [74]. As a third possibility, demographic and range expansions of Yarkand hare $[8,20,78]$ might have supported extensive gene flow among populations.

The coexistence of genetic differentiation and gene flow of Yarkand hare populations is not a surprising result considering the environmental, geological, and evolutionary history. Climatic fluctuations in the Pleistocene as well as mountain and plateau uplift around the Tarim Basin are likely important factors in the differentiation and migration of basin hare populations. Based on highquality SNP analysis, the most recent common ancestor of Lepus yarkandensis and Lepus timidus was estimated to have occurred approximately 0.86 Mya (Fig. 3a). This time interval is consistent with a period of desertification in the Tarim Basin, during which a drought climate and desert-like habitat began to dominate the entire basin $[79,80]$. This occurred during the middle Pleistocene transition (approximately $1.25-0.70$ Mya) [81] and following the formation of the Taklimakan Desert (approximately 5.3 Mya) [16, 82]. During this period, the hare ancestors gradually adapted to the dry environment of the basin, eventually evolving into the Yarkand hare. The divergence time of Yarkand hare (0.86 Mya) estimated herein is in agreement with the results obtained from mitochondrial genes (0.83 Mya [8]; 0.84 Mya [83]), combined with numerous accurate fossil datasets. Notably, this divergence time is similar to that of other species currently living around the Tarim Basin, including Cervus elaphus yarkandensis (0.8-2.2 Mya [73]; 0.98 Mya [84]), and with the timing of the most recent common ancestor Phrynocephalus axillaris (0.88 Mya) and the appearance of Phrynocephalus forsythii in the Tarim Basin (0.94 Mya) [85].

Divergence among the Yarkand hare populations may have resulted from glacial-induced fragmentation and follow-up recolonization during the early/middle Pleistocene. The KS population, located at the root of the phylogenetic tree with high genetic diversity, was estimated to have been the first Yarkand hare population to have diverged approximately $0.81-0.49$ Mya (Fig. 3a), confirming its relatively older evolutionary history and further 
suggesting that the earliest Yarkand hare ancestor population may have inhabited the area near the Kashgar oasis in the southwest of the basin.

Approximately 0.880-0.5 Mya, rapid uplift of the Tibetan-Pamir Plateau as well as reduced air circulation strength and rainfall in the Tianshan Mountains further enhanced the aridity of the Tarim Basin and expanded the Taklimakan Desert [79]. Simultaneously, during the global ice maximum 0.7-0.6 Mya, maximum glaciation occurred in the Tibetan Plateau, likely reducing the amount of water vapor conveyed by the westerly winds to the Tarim Basin, resulting in extreme desert expansion $[86,87]$. Hare populations in the basin would have had to spread toward the refugia to develop suitable habitats, which match the differentiation time of the southwestern populations 0.8-0.49 Mya (Fig. 3a). Divergence events of other populations occurred approximately $0.46-0.32$ Mya (Fig. 3a), during the great interglaciation period (0.5-0.3 Mya) of the Pleistocene, where the basin climate was likely warmer and moister than that in the former sub-stage $[75,88]$. As temperatures increased, the river systems along the edge of the Tarim Basin were flooded with greater amounts of runoff from melting snow and glacial ice [89]. Importantly, mesophytic herbaceous plants in the basin were widely distributed 0.4-0.25 Mya [88], which would be effective at dispersing hares toward the outside of the refugia, thereby contributing to the evolution and formation of northern populations (0.360.34 Mya) (Fig. 3a).

Subsequently, during the Penultimate (0.3-0.13 Mya) and Yurunkax glaciation $(0.333 \pm 0.046$ Mya $)$ [90] of the West Kunlun Mountains [75, 90], the basin climate became increasingly cold and arid, with a significantly reduced amount of melting glacial snow in the summer that contributed to the drying up of rivers. This resulted in the shrinkage or fragmentation of the original habitat of Yarkand hares, causing their retreat toward the southwestern refugia.

Based on our results and previous studies [15, 19, 20], the pattern of historical gene flow and divergence times of the southwest and north group Yarkand hare populations can be hypothesized as follows: the species originated from the southwestern parts of the Tarim Basin, expanding north during interglacial periods and contracting to the southwestern areas during glacial periods. Such repeated differentiation and recolonization events may have promoted the range expansion of the Yarkand hares, followed by extensive gene flow among populations. However, due to limited Tarim Basin sampling sites, our prediction regarding the migration of Yarkand hare involves only the southwestern and northern regions of the Tarim Basin, which have been recognized as the key areas for glacial refuge and migration events based on previous mtDNA results [15]. Therefore, the generalization of our predictions for the entire range of the species must be verified by including southeast samples in similar analyses in the future.

\section{Unique characteristics of the TX population}

In contrast to other samples from the oases or mountains around the basin, samples from the TX population were collected from the Pamir Plateau in the upper reaches of Yarkand River, near the southwestern region of the Tarim Basin. Surprisingly, all TX samples were completely separated from the southwest group in PCA and instead clustered with north group samples in the phylogenetic tree (Fig. 2). ADMIXTURE Bayesian clustering analysis also showed that the TX population was independent of a pure ancestor when $K=3$. In addition, all individuals from the ALR population in the north group, as well as some KRL individuals, had large proportions of samples in the TX lineage ( $K=3$, Fig. 2c). Our results suggest that patterns of admixture in TX, ALR, and KRL populations between the southwestern and north groups may have resulted from migration events (Fig. 3b). Furthermore, the low pairwise $F_{\mathrm{ST}}$ values between the TX and north group populations (Table 2) indicated their close phylogenetic relationship, suggesting that they may have originated from the same ancestral migration population and insufficient time has passed for their divergence, despite their current geographical isolation [30]. These migration events were further verified using TreeMix analyses (Fig. 3b). Considering the above results and those of previous studies $[8,15,19]$, we deduced that during Penultimate Glaciation (0.3-0.13 Mya), the habitats of the north group population were fragmented due to river disruption and oasis shrinkage caused by cold and dry weather along with reduced glacial meltwater. One of the ancestral migration populations was estimated to have diverged from the north populations 0.32 Mya (Fig. 3a), initially spreading from the southwestern regions of the Tarim Basin during the interglacial period and then returning to the southwestern refuge during the second stage of the Penultimate Glacial Period (0.277-0.266 Mya) in the West Kunlun Mountains [91]. During the southwestern dispersal, some hares migrated upstream and dispersed alongside Yarkand River, eventually arriving at Tashkurgan County, where they formed the TX population. Ultimately, the climate became colder and drier during the ice age, and this population adapted to the distinct plateau environment, remaining isolated from other southwest hare populations.

\section{Selection signatures in Yarkand hare populations}

The Yarkand hare is a typical drought-tolerant hare endemic to the Tarim Basin around the Taklimakan 
Desert in Xinjiang, China. In particular, this species has adapted to extreme aridity, intense solar radiation, large diurnal temperature variations, and hot environments [15]. To characterize the regions with environmental differences among the sampled Yarkand hare populations, we conducted selective sweep analysis and identified several candidate genes with a high degree of differentiation (Additional file 5: Table S2).

Different genes selected in the north [e.g., F-box and WD repeat domain containing 8 (FBXW8)] and southwest [e.g., aryl hydrocarbon receptor nuclear translocator like (ARNTL), heat shock protein 90 beta family member 1 (HSP90B1), and ubiquitination factor E4B (UBE4B)] groups were significantly enriched in the same catabolic and metabolic processes, as well as in the corticosteroid and glucocorticoid receptor signaling pathways; these genes were also commonly enriched in developmentrelated GO terms (Additional file 6: Table S3). These candidate genes and their associated biological processes indicate the importance of energy supplementation for the Yarkand hare to adapt to extreme drought environments with saline-alkaline soil and poor food resources. A similar assumption was made based on whole-genome sequencing data of Tarim red deer (C.e. yarkandensis) and sheep breeds (Ovis aries) indicating adaptation to extreme drought environments [84, 92]. Two candidate genes, laminin subunit beta 1 (LAMB1) and integrin subunit alpha 1 (ITGA1), selected in the southwest group were significantly enriched in pathways related to cell survival and proliferation, including ECM-receptor interaction (KEGG pathway accession code: ocu04512), PI3K-AKT signaling (KEGG pathway accession code: ocu04151), and focal adhesion pathway (KEGG pathway accession code: ocu04510) (Additional file 6: Table S3). These pathways are explicitly associated with responses of the lung, heart, and spleen of yak to altered elevation, and have been shown to play a pivotal role in the adaptation of yak to hypoxia [93]. In addition to arid adaptation, the southwest populations of the Yarkand hare also live at higher altitudes $(>1500 \mathrm{~m}$ above sea level) than those in the north. Therefore, we speculated that these pathways and related candidate genes may explain the potential molecular mechanisms underlying the adaptation of southwest Yarkand hare populations to hypobaric hypoxia in medium-altitude areas. This suggests that specific factors influencing natural selection may act on similar functional biological pathways in different species, driving their adaptation to the same environments.

We identified 17 candidate genes via putative selection sweeps between north populations and the TX population, only three of which were selected in the north group. The biological processes and pathway functions of the other 14 genes selected in the TX population indicate that the special environment may have forcibly shaped the genomic differentiation in this population (Additional file 7: Table S4); this may be associated with survival of the Yarkand hare in a cold, arid, and high-altitude environment. For instance, the candidate gene polycystin-2, transient receptor potential cation channel (PKD2) selected in TX encodes an integral membrane glycoprotein [94] that is similar to calcium channel subunits and is required for the development of a normal renal tubular architecture [95]. PKD2 was significantly enriched in several GO biological process terms, including kidney and renal system-related morphogenesis and development, sodium channel activity, response to water stimulus, and response to osmotic stress (Additional file 7: Table S4). All of these GO terms are functionally related to regulating water reabsorption, renal cell metabolism, and blood vessels in the kidney, and may therefore enable the Yarkand hare TX population to reabsorb water more efficiently in an arid environment. PKD2 and three other genes selected in TX [ALK receptor tyrosine kinase $(A L K)$, fibrillin $2(F B N 2)$, and $\alpha$-kinase anchoring protein 6 (AKAP6)] were significantly associated with responses to various stimuli (eight $\mathrm{GO}$ terms, $p<0.05$; Additional file 7: Table S4), indicating that these genes and GO terms may be functionally related to hypoxia responses in the plateau environment of TX. Notably, another candidate selected gene in TX, cytochrome P450, family 4, subfamily A, polypeptide 5 (CYP4A5), was significantly enriched in the KEGG pathways fatty acid degradation (KEGG pathway accession code: ocu00830), retinol metabolism (KEGG pathway accession code: ocu05223), and arachidonic acid metabolism pathway (KEGG pathway accession code: ocu00590). CYP4A5 plays an important role in converting arachidonic acid into 19(S)-HETE and 20-HETE through $\omega$-hydroxylation (Additional file 7: Table S4). 19(S)-HETE has been reported as a potent vasodilator of renal preglomerular vessels that stimulate water reabsorption [96]. Interestingly, the arachidonic acid metabolism pathway is a key molecular mechanism underlying mammalian adaptation to arid deserts [84, 92, 97]. 20-HETE substantially affects renal tubular and vascular function [98] by regulating vasodilation and contraction, as well as by promoting endothelial cell proliferation and angiogenesis. The balance between vascular contraction and relaxation plays a pivotal role in hypoxia-induced pulmonary arterial hypertension [99] and congestive heart failure [100]. Therefore, we speculate that the candidate gene CYP4A5 may play an essential role in survival of the Yarkand hare TX population in arid and altitude environments. Nevertheless, the specific roles of these candidate genes require further validation.

Besides drought stress, intense solar radiation is another major environmental factor affecting the survival 
of Yarkand hares in the Tarim Basin under altituderelated hypoxic conditions. Chronic exposure to solar UV radiation is a potent inducer of reactive oxygen species (ROS). Oxidative damage is induced by oxidative stress when ROS formation exceeds the antioxidant defense capacity of target cells and is associated with various disease states [101]. The candidate genes identified in the southwest group, such as oxidation resistance 1 (OXR1), and in the TX population, such as leucine rich repeat kinase 2 (LRRK2), were significantly enriched in $18 \mathrm{GO}$ terms related to the regulation and response to oxidative stress and peroxidase activity (Additional file 8: Table S5); this indicates that under stress conditions, these genes protect cells from oxidative stress-induced damage [102, 103]. Such regulation of the cellular stress response may play an important role in the adaptation of these populations to harsh environments. Furthermore, the candidate gene dedicator of cytokinesis 7 (DOCK7) selected in TX is involved in the regulation of smooth muscle cell and vascular-associated smooth muscle cell migration (Additional file 8: Table S5). LRRK2 and DOCK7 were also significantly enriched in five biological process terms (GO: 0008021, GO: 0031398, GO: 0010038, GO: 0017016, and GO: 0006979, $p<0.05$; Additional file 8: Table S5) that were previously identified as lineage-specific processes associated with the adaptation of yak to high altitudes [104]. Accordingly, we assumed that LRRK2 and DOCK7 may have potential roles in the adaptation of Yarkand hare populations to cold and high-altitude environments. Nevertheless, these functions need to be confirmed by functional analysis of the identified genes with traits of adaptive evolution in comparative stress studies of Yarkand hare and other animals living at high altitudes.

Overall, we detected only a small number of candidate genes (58) within selected regions among Yarkand hare populations, which may be attributed to the limited sampling sites or the small and unequal sample sizes for the southwest group and TX population. Moreover, the reduced-representation sequencing approach-which may not detect low-frequency alleles that could have a substantial role in adaptation - exhibits some inherent limitations with respect to obtaining information regarding neutral or adaptive genetic variation on a genomewide scale [29]. Because of these limitations, we have not considered more stringent settings for $p$-values, such as Bonferroni correction, false discovery rate, and fold enrichment tests. Nonetheless, we identified noteworthy, overrepresented biological processes and pathways based on raw $p$-values, which may provide insights into the mechanisms involved in the environmental adaptation of this species. It is also important to note that many evolutionary processes can influence genomic variation. Without functional experiments, it is difficult to distinguish natural selection from genetic drift at a particular locus, which includes the candidate genes identified herein. Therefore, comprehensive studies integrating wholegenome re-sequencing, demographic history, candidate gene sequencing, and transcriptomes with adaptive traits and physiological mechanisms of Yarkand hare are warranted to confirm or refine our functional genomic hypotheses and further explore the genomic mechanisms underlying adaptation.

\section{Conclusions}

We performed SNP analysis via SLAF-seq to elucidate the genetic diversity, differentiation, phylogenetic relationships, historical pattern of divergence, and gene flow among seven Yarkand hare populations in the southwestern and northern regions of the Tarim Basin at the genome-wide level. We also conducted selective sweep analysis to assess differences in the SNP distribution across chromosomes and determine their associations with environmental stress or adaptation.

Our genomic data revealed a relatively high degree of genetic diversity along with a high degree of admixture between populations through multiple analyses, although there was a clear population structure and low to moderate differentiation between the southwest and north groups. The coexistence of genetic differentiation and admixture among the Yarkand hare populations sampled in this study likely reflects the strong adaptability and enhanced dispersal characteristics of this species, as well as the important influence of historical and current environmental changes. We further investigated the selection signatures that may be caused by different types of environmental selective pressure, and identified genes and pathways that may be related to drought environment adaptation of the Yarkand hare. We also screened genes and pathways likely associated with altitude adaptation of the TX and southwest populations. Overall, this study highlights the value of genomic data in assessing the population genetics of this endemic species, thereby prompting future gene linkage and association analyses of key adaptive traits linked to the specific habitats of these and other hare populations.

\section{Supplementary Information}

The online version contains supplementary material available at https://doi. org/10.1186/s12983-021-00432-x.

Additional file 1: Table S1. Summary of Yarkand hare sequencing data obtained in this study.

Additional file 2: Figure S1. Distribution of SLAF tags on reference genome chromosomes. The abscissa represents the SLAF tag position on the chromosome and the ordinate represents each chromosome. The reference genome was divided into 1-Mb portions. The higher the number 
of SLAF tags per $1 \mathrm{Mb}$, the darker the color; the lower the number, the lighter the color.

Additional file 3: Figure S2. Phylogenetic trees constructed using ML (a) and BI (b) methods based on the SNP matrix of 76 Yarkand hares. Oryctolagus cuniculus was used as the outgroup. AKS, Akesu; ALR, Alar; KRL, Korla; TX Taxkorgan; AKT, Aketu; KS, Kashgar; WQ, Wuqia.

Additional file 4: Figure S3. Cross-validation errors in the ADMIXTURE analysis. The number of ancestry $(K)$ was assumed to range from 1 to $10 ; \mathrm{K}$ $=2$ was the optimal number.

Additional file 5: Table S2. List of genes in the overlapping regions selected by the top $5 \%$ highest $\log _{2}\left(\theta_{\pi}\right.$ ratio) and top $5 \%$ highest $F_{\text {ST }}$ values for Yarkand hare populations from different environments.

Additional file 6: Table S3. The top 20 KEGG pathways and GO functional enrichment of candidate genes between the north and southwest groups via $F_{S T}-\theta_{\pi}$ ratio analysis.

Additional file 7: Table S4. KEGG pathways and GO functional enrichment of candidate genes between the north group and TX population via $F_{S T}-\theta_{\pi}$ ratio analysis.

Additional file 8: Table S5. KEGG pathways and GO functional enrichment of candidate genes between the southwest group and TX population via $F_{S T}-\theta_{\pi}$ ratio analysis.

\section{Acknowledgements}

We thank Lifu Liao from the Xinjiang Center for Disease Control and Mamtimin Sulayman from Xinjiang University for assisting with sample collection. This work was supported by the National Natural Science Foundation of China (No. 31860599, 31301006). We also acknowledge the support from the Natural Science Foundation Project of Xinjiang Uygur Autonomous Region (No. 2018D01C060).

\section{Authors' contributions}

Shan WJ conceived and designed the study. Dai HY and Shan WJ collected the samples. Zhang YC performed the experiments. Ababaikeri B and Zhang YC analyzed the data, interpreted the results, and wrote the manuscript. Ababaikeri B and Shan WJ edited the manuscript. All authors read and approved the final version of the manuscript.

\section{Funding}

This work was funded by the National Natural Science Foundation of China (No. 31860599, 31301006) and the Natural Science Foundation Project of Xinjiang Uygur Autonomous Region (No. 2018D01C060).

\section{Availability of data and materials}

The data that support the findings of this study have been deposited into CNGB Sequence Archive (CNSA) [105] of China National GeneBank DataBase (CNGBdb) [106] with accession number CNP0001925. The sequence data in our study has been uploaded to NCBI/Genbank with the accession number of PRJNA750896 and can be accessed under: https://www.ncbi.nlm.nih.gov/sra/ PRJNA750896.

\section{Declarations}

\section{Ethics approval and consent to participate}

The samples used in this study were conducted in strict accordance with the Animal Ethics Procedures and Guidelines of the People's Republic of China.

\section{Consent for publication}

Not applicable.

\section{Competing interests}

The authors declare that they have no competing interests.

\section{Author details}

'Xinjiang Key Laboratory of Biological Resources and Genetic Engineering, College of Life Science and Technology, Xinjiang University, Urumqi 830046, China. ${ }^{2}$ College of Xinjiang Uyghur Medicine, Hoten 848000, Xinjiang, China.
Received: 11 January 2021 Accepted: 7 September 2021

Published online: 26 September 2021

\section{References}

1. Fumagalli M, Vieira FG, Korneliussen TS, Linderoth T, Huerta-Sánchez E, Albrechtsen A, et al. Quantifying population genetic differentiation from Next-Generation Sequencing data. Genetics. 2013;195:979-92.

2. Wright S. The genetical structure of populations. Ann Eugenics. 1951;15:323-54.

3. Nevo E, Cleve H. Genetic differentiation during speciation. Nature. 1978:275:125-6.

4. Freeland JR, Kirk H, Peterson SD. Molecular ecology. 2nd ed. Oxford: Wiley-Blackwell; 2011.

5. Geert AV, Rossum FV, Triest L. Genetic diversity in adult and seedling populations of Primula vulgaris in a fragmented agricultural landscape. Conserv Genet. 2008;9:845-53.

6. Frankham R, Ballou JD, Briscoe DA. Introduction to conservation genetics. 2nd ed. Cambridge: Cambridge University Press; 2010.

7. Debapriyo C, Uma R, Anindya S. Quaternary climate change and social behavior shaped the genetic differentiation of an endangered montane primate from the southern edge of the Tibetan Plateau. Am J Primatol. 2015:77:271-84.

8. Kumar B, Cheng JL, Ge DY, Xia L, Yang QS. Phylogeography and ecological niche modeling unravel the evolutionary history of the Yarkand hare, Lepus yarkandensis (Mammalia: Leporidae), through the Quaternary. BMC Evol Biol. 2019;19:113.

9. Sosa-Pivatto M, Camps GA, Baranzelli M, Espíndola A, Sérsic AN, et al. Connection, isolation and reconnection: Quaternary climatic oscillations and the Andes shaped the phylogeographical patterns of the Patagonian bee Centris cineraria (Apidae). Biol J Linn Soc. 2020;131:396-416.

10. Haag T, Santos AS, Sana DA, Morato RG, Cullen L, Crawshaw PG, et al. The effect of habitat fragmentation on the genetic structure of a top predator: loss of diversity and high differentiation among remnant populations of Atlantic Forest jaguars (Panthera onca). Mol Ecol. 2010;19:4906-21.

11. Ony MA, Nowicki M, Boggess SL, Klingeman WE, Zobel JM, Trigiano RN, et al. Habitat fragmentation influences genetic diversity and differentiation: Fine-scale population structure of Cercis canadensis (eastern redbud). Ecol Evol. 2020;00:1-16.

12. Kolb A, Diekmann M. Effects of life-history traits on responses of plant species to forest fragmentation. Conserv Biol. 2005;19:929-38.

13. Gao YT. Current studies on the Chinese Yarkand hare. Ann Zool Fenn. 1983:17:23-5.

14. Liu J, Li Y, Arnold ML, Wu CH, Wu SF, Lu X, et al. Reticulate evolution: frequent introgressive hybridization among chinese hares (genus lepus) revealed by analyses of multiple mitochondrial and nuclear DNA loci. BMC Evol Biol. 2011;11:223.

15. Shan WJ, Liu J, Yu L, Murphy RW, Mahmut H, Zhang YP. Genetic consequences of postglacial colonization by the endemic Yarkand hare (Lepus yarkandensis) of the arid Tarim Basin. Sci Bull. 2011;56:1370-82.

16. Sun JM, Zhang $L Y$, Deng $C L$, Zhu RX. Evidence for enhanced aridity in the Tarim Basin of China since 5.3 Ma. Quat Sci Rev. 2008;27:1012-23.

17. Wang S. China red data book of endangered animals. Beijing: Science Press; 1998. ((In Chinese)).

18. Smith AT, Johnston CH. Lepus yarkandensis. In: The IUCN Red List of Threatened Species; 2016. eT11796A115103994 Downloaded on 22 August 2020.

19. Li ZC, Xia L, Li YM, Yang QS, Liang MY. Mitochondrial DNA variation and population structure of the yarkand hare Lepus yarkandensis. Acta Theriol. 2006;51:243-53.

20. Wu YH, Xia L, Zhang Q, Yang QS. Habitat fragmentation affects genetic diversity and differentiation of the Yarkand hare. Conserv Genet. 2010;11:183-94.

21. Wu YH, Xia L, Zhang Q, Lei FM, Yang QS. Genetic diversity in the male-specific SRY gene of Lepus yarkandensis. Chinese Sci Bull. 2010;55:834-40

22. Yin JL, Fang ZW, Sun C, Zhang P, Zhang X, Lu C, et al. Rapid identification of stripe rust resistant gene in a space-induced wheat mutant 
using specific length amplified fragment (SLAF) sequencing. Sci Rep. 2018:8:3086.

23. Qin M, Li C, Li Z, Chen W, Zeng Y. Genetic diversities and differentially selected regions between Shandong indigenous pig breeds and western pig breeds. Front Genet. 2020;10:1351.

24. Yang TY, Meng W, Guo BC. Population genomic analysis of two endemic Schizothoracins reveals their genetic differences and underlying selection associated with altitude and temperature. Animals. 2020;10:447.

25. Zhang YQ, Luan PX, Ren GM, Hu G, Yin JS. Estimating the inbreeding level and genetic relatedness in an isolated population of critically endangered Sichuan taimen (Hucho Bleekeri) using genome-wide SNP markers. Ecol Evol. 2020;10:1390-400.

26. Stevens SM. Population differentiation, dispersal limitation, and local adaptation in the gametophytic fern Vittaria appalachiana. Ph.D. thesis, Purdue University, West Lafayette, Indiana. 2014.

27. Orsini L, Vanoverbeke J, Swillen I, Mergeay J, Meester L. Drivers of population genetic differentiation in the wild: isolation by dispersal limitation, isolation by adaptation and isolation by colonization. Mol Ecol. 2013;22:5983-99.

28. Friesen VL, Burg TM, McCoy KD. Mechanisms of population differentiation in seabirds. Mol Ecol. 2007;16:1765-85.

29. Wang J, Feng C, Jiao TL, Von Wettberg EB, Kang M. Genomic signature of adaptive divergence despite strong non-adaptive forces on edaphic Islands: a case study of Primulina juliae. Genome Biol Evol. 2017;9:3495-508.

30. Clucas GV, Younger JL, Kao DM, Rogers AD, Handley J, Miller GD, et al. Dispersal in the sub-Antarctic: king penguins show remarkably little population genetic differentiation across their range. BMC Evol Biol. 2016;16:211.

31. Andersson $L$, Georges M. Domestic animal genomics: deciphering the genetics of complex traits. Nat Rev Genet. 2004;5:202-12.

32. Psifidi A, Dovas $\mathrm{Cl}$, Banos $\mathrm{G}$. A comparison of six methods for genomic DNA extraction suitable for PCR-based genotyping applications using ovine milk samples. Mol Cell Probes. 2010;24:93-8.

33. Lindblad-Toh K, Manuel G, Or Z, Michael FL, Brian JP, Stefan W, et al. A high-resolution map of human evolutionary constraint using 29 mammals. Nature. 2011;478:476-82.

34. Sun XW, Liu DY, Zhang XF, Li WB, Liu H, Hong WG, et al. SLAF-seq: An efficient method of large-scale De Novo SNP discovery and genotyping using high-throughput sequencing. PLOS ONE. 2013;8:e58700.

35. Zhang YX, Wang LH, Xin HG, Li DH, Ma CX, Ding X, et al. Construction of a high-density genetic map for sesame based on large scale marker development by specific length amplified fragment (SLAF) sequencing. BMC Plant Biol. 2013;13:141.

36. Li RQ, Yu C, Li YR, Lam TW, Yiu SM, Kristiansen K, et al. SOAP2: an improved ultrafast tool for short read alignment. Bioinformatics. 2009;25:1966-7.

37. Li H, Durbin R. Fast and accurate long-read alignment with BurrowsWheeler transform. Bioinformatics. 2010;26:589-95.

38. Li H, Handsaker B, Wysoker A, Fennell T, Ruan J, Homer N, et al. The sequence alignment/map format and SAMtools. Bioinformatics. 2009:25:2078-9.

39. Mckenna A, Hanna M, Banks E, Sivachenko A, Cibulskis K, Kernytsky $A$, et al. The genome analysis toolkit: a map reduce framework for analyzing next-generation DNA sequencing data. Genome Res. 2010;20:1297-303.

40. Purcell S, Neale B, Todd-Brown K, Thomas L, Ferreira MAR, Bender D, et al. PLINK: a tool set for whole-genome association and populationbased linkage analyses. Am J Hum Genet. 2007:81:559-75.

41. Excoffier L, Lischer HEL. Arlequin suite ver 3.5: a new series of programs to perform population genetics analyses under Linux and Windows. Mol Ecol Resour. 2010;10:564-7.

42. Liu K, Muse SV. PowerMarker: an integrated analysis environment for genetic marker analysis. Bioinformatics. 2005;21:2128-9.

43. Aberer AJ, Kassian K, Alexandros S. ExaBayes: massively parallel bayesian tree inference for the whole-genome era. Mol Biol Evol. 2014;31:2553-6.

44. Nguyen L, Schmidt HA, von Haeseler A, Minh BQ. IQ-TREE: a fast and effective stochastic algorithm for estimating maximum-likelihood phylogenies. Mol Biol Evol. 2015;32:268-74.
45. Kalyaanamoorthy S, Minh BQ, Wong TKF, Haeseler AV, Jermiin LS. ModelFinder: fast model selection for accurate phylogenetic estimates. Nat Methods. 2017;14:587-9.

46. Price AL, Patterson NJ, Plenge RM, Weinblatt ME, Shadick NA, Reich D. Principal components analysis corrects for stratification in genomewide association studies. Nat Genet. 2006;38:904-9.

47. Alexander DH, Novembre J, Lange K. Fast model-based estimation of ancestry in unrelated individuals. Genome Res. 2009;19:1655-64.

48. Alexander DH, Lange K. Enhancements to the ADMIXTURE algorithm for individual ancestry estimation. BMC Bioinform. 2011;12:e246.

49. Yang ZH. PAML 4: phylogenetic analysis by maximum likelihood. Mol Biol Evol. 2007;24:1586-91.

50. Wu CH, Wu JP, Bunch TD, Li QW, Wang YX, Zhang YP. Molecular phylogenetics and biogeography of Lepus in eastern Asia based on mitochondrial DNA sequences. Mol Phylogenet Evol. 2005;37:45-61.

51. Matthee CA, Vuuren BJV, Bell D, Robinson TJ. A molecular supermatrix of the rabbits and hares (Leporidae) allows for the identification of five intercontinental exchanges during the Miocene. Syst Biol. 2004;53:433-47.

52. Pickrell JK, Pritchard JK, Tang H. Inference of population splits and mixtures from genome-wide allele frequency data. Plos Genet. 2012;8:e1002967.

53. Danecek P, Auton A, Abecasis G, Albers CA, Banks E, DePristo MA, et al. The variant call format and VCFtools. Bioinformatics. 2011;27:2156-8.

54. Mahram A, Herbordt MC. Ncbi blastp on high-performance reconfigurable computing systems. ACM Trans Reconfig Technol Syst. 2015;7:1-20.

55. Conesa A, Gotz S, Garcia-Gomez JM, Terol J, Talon M, Robles M. Blast2go: a universal tool for annotation, visualization and analysis in functional genomics research. Bioinformatics. 2005;21:3674-6.

56. Moriya Y, Itoh M, Okuda S, Yoshizawa AC, Kanehisa M. KAAS: an automatic genome annotation and pathway reconstruction server. Nucleic Acids Res. 2007;35:W182-5.

57. Yu G, Wang LG, Han Y, He QY. ClusterProfiler: an R package for comparing biological themes among gene clusters. OMICS. 2012;16:284-7.

58. Carneiro M, Afonso S, Geraldes A, Garreau H, Bolet G, Boucher $\mathrm{S}$, et al. The genetic structure of domestic rabbits. Mol Biol Evol. 2011;28:1801-16

59. Carneiro M, Albert FW, Melo-Ferreira J, Galtier N, Gayral P, Blanco-Aguiar $J A$, et al. Evidence for widespread positive and purifying selection across the European rabbit (Oryctolagus cuniculus) genome. Mol Biol Evol. 2012:29:1837-49.

60. Wang GD, Zhai W, Yang HC, Lu W, Zhong L, Liu YH, et al. Out of southern East Asia: the natural history of domestic dogs across the world. Cell Res. 2016;26:21-33.

61. Ai HS, Fang XD, Yang B, Huang ZY, Chen H, Mao LK, et al. Adaptation and possible ancient interspecies introgression in pigs identified by whole-genome sequencing. Nat Genet. 2015;47:217-25.

62. Sarkissian CD, Ermini L, Schubert M, Yang MA, Librado P, Fumagalli M, et al. Evolutionary genomics and conservation of the endangered Przewalski's horse. Curr Biol. 2015;25:2577-83.

63. Ren A, Du K, Jia X, Yang R, Wang J, Chen SY, et al. Genetic diversity and population structure of four Chinese rabbit breeds. PLOS ONE. 2019;14:e0222503.

64. Carneiro M, Rubin CJ, Palma FD, Albert FW, Alföldi J, Barrio AM, et al. Rabbit genome analysis reveals a polygenic basis for phenotypic change during domestication. Science. 2014;345:1074-9.

65. Ababaikeri B, Ning LQ, Eli S, Ismayil Z, Halik M. Microsatellite analyses of genetic diversity and population structure of goitered gazelle Gazella subgutturosa (Güldenstädt, 1780) (Artiodactyla: Bovidae) in Xinjiang. China Acta Zool Bulg. 2019;71:407-16.

66. Shan WJ, Mahmut H. Primary study on genetic diversity of Lepus yarkandensis. Biotechnology. 2013;023:46-9 ((In Chinese)).

67. Aerziguli S, Mairepati P, Dilixiati A, Mahemut H. The comparison of skull morphology of Yarkand hare (Lepus yarkandensis) different geographical populations. Xinjiang Agricul Sci. 2010;47:1627-31 ((In Chinese)).

68. Xue LQ, Yang F, Yang CB, Chen XF, Zhang LC, Chi YX, et al. Identification of potential impacts of climate change and anthropogenic activities on stream flow alterations in the Tarim River basin. China Sci Rep. 2017;7:8254. 
69. Bruelheide H, Jandt U, Gries D, Thomas FM, Foetzki A, Göttengen, et al. Vegetation changes in a river oasis on the southern rim of the Taklamakan Desert in China between 1956 and 2000. Phytocoenologia. 2003;33:801-18

70. Fan ZL, Ma YJ, Alishir K, Shen YL. On formation, evolution and sustainable development of artificial oases ecosystem in desert area in China. J Desert Res. 2004;24:10-6.

71. Tzedakis PC, Lawson IT, Frogley MR, Hewitt GM, Preece RC. Buffered tree population changes in a quaternary refugium: evolutionary implications. Science. 2002;297:2044-7.

72. Ketchum RN, Smith EG, DeBiasse MB, Vaughan GO, McParland D, Leach WB, et al. Population genomic analyses of the sea urchin Echinometra sp. EZ across an extreme environmental gradient. Genome Biol Evol. 2020;12:1819-29.

73. Hu PF, Shao YC, Xu JP, Wang TJ, Li YQ, Liu HM, et al. Genome-wide study on genetic diversity and phylogeny of five species in the genus Cervus. BMC Genomics. 2019;20:384.

74. Hewitt GM. Some genetic consequences of ice ages, and their role in divergence and speciation. Biol J Linn Soc. 1996;58:247-76.

75. Zheng BX, Xu QQ, Shen YP. The relationship between climate change and Quaternary glacial cycles on the Qinghai-Tibetan Plateau: review and speculation. Quatern Int. 2002;97-98:93-101.

76. Su ZH, Zhang ML, Cohen Jl. Phylogeographic and demographic effects of Quaternary climate oscillations in Hexinia polydichotoma (Asteraceae) in Tarim Basin and adjacent areas. Plant Syst Evol. 2012;298:1767-76.

77. Ehlers J, Gibbard PL. The extentand chronology of Cenozoicglobal glaciation. Quatern Int. 2007;164:6-20.

78. Wu Y, Xia L, Zhang Q, Yang QS, Meng XX. Bidirectional introgressive hybridization between Lepus capensis and Lepus yarkandensis. Mol Phylogenet Evol. 2011;59:545-55.

79. Fang XF, Pang LQ, Yang SL, Li JJ, An ZS, Jiang PA, et al. Loess in Kunlun Mountains and its implications on desert development and Tibetan Plateau uplift in west China. Science in Cina (Series D). 2002;45:290-9.

80. Zhang ZG, Han WX, Fang XM, Song CH, Li XY. Late Miocene-Pleistocene aridification of Asian inland revealed by geochemical records of lacustrinefan delta sediments from the western Tarim Basin. NW China Palaeogeogr Palaeocl. 2013;377:52-61.

81. Clark PU, Archer D, Pollard D, Blum JD, Rial JA, Brovkin V, et al. The middle Pleistocene transition: characteristics, mechanisms, and implications for long-term changes in atmospheric $\mathrm{pCO}_{2}$. Quat Sci Rev. 2006;25:3150-84.

82. Sun JM, Liu TS. The age of the Taklimakan Desert. Science. 2006;312:1621.

83. Ge DY, Wen ZX, Xia L, Zhang ZQ, Erbajeva M, Huang CM, et al. Evolutionary history of Lagomorphs in response to global environmental change. PLoS ONE. 2013;8:e59668.

84. Ababaikeri B, Abduriyim S, Tohetahong Y, Mamat T, Ahmat A, Halik M. Whole-genome sequencing of Tarim red deer (Cervus elaphus yarkandensis) reveals demographic history and adaptations to an arid-desert environment. Front Zool. 2020;17:31.

85. Zhang Q, Xia L, He JB, Wu YH, Fu JZ, Yang QS. Comparison of phylogeographic structure and population history of two Phrynocephalus species in the Tarim Basin and adjacent areas. Mol Phylogenet Evol. 2010;57:1091-104.

86. Lu HY, Guo ZT. Evolution of the monsoon and dry climate in East Asia during late Cenozoic: a review. Sci China Earth Sci. 2014;57:70-9.

87. Wu GJ, Pan BT, Guan QY, Gao HS. The Maximum Glaciation and desert expansion in China during MIS16. Journal of glaciology and geocryology. 2002;24:544-9 ((In Chinese))
88. Wu FL, Fang XM, Miao YF. Aridification history of the West Kunlun Mountains since the mid-Pleistocene based on sporopollen and microcharcoal records. Palaeogeogr Palaeocl. 2020;547:109680.

89. Shi YF, Cui ZJ, Su Z. The Quaternary glaciations and environmental variations in China. Shijiazhuang: Hebei Science and Technology Press; 2006 p. 618. (in Chinese)

90. Zheng BX, Jiao KQ, Li SJ, Liu JQ. New progress in the study of Quaternary glacial age in the Tibetan Plateau: a case study of the West Kunlun Mountains. Chin Sci Bull. 1990;7:533-7 ((In Chinese))

91. Yi CL, Cui ZJ, Xiong HH. Numerical periods of Quaternary glaciations in China. Quaternary Sci. 2005;25:609-19 ((In Chinese)).

92. Yang J, Li WR, Lv FH, He SG, Tian SL, Peng WF, et al. Whole-genome sequencing of native sheep provides insights into rapid adaptations to extreme environments. Mol Biol Evol. 2016;33:2576-92.

93. Qi XB, Zhang Q, He YX, Yang LX, Zhang XM, Shi P, et al. The transcriptomic landscape of yaks reveals molecular pathways for high altitude adaptation. Genome Biol Evol. 2019;11:72-85.

94. Cai Y, Maeda Y, Cedzich A, Torres VE, Somlo S. Identification and characterization of polycystin-2, the PKD2 gene product. J Biol Chem. 1999:274:28557-65.

95. Mochizuki T, Wu GQ, Hayashi T, Xenophontos SL, Veldhuisen B, Saris $\mathrm{J}$, et al. PKD2, a gene for polycystic kidney disease that encodes an integral membrane protein. Science. 1996;272:1339-42.

96. Carroll MA, Balazy M, Margiotta P, Huang DD, Falck JR, McGiff JC, et al. Cytochrome P-450-dependent HETEs: profile of biological activity and stimulation by vasoactive peptides. Am J Physiol Regul Integr Comp Physiol. 1996;271:R863-9.

97. Jirimutu WZ, Ding G, Chen G, Sun Y, Sun Z, Zhang H, et al. Genome sequences of wild and domestic Bactrian camels. Nat Commun. 2012;3:1202.

98. Schwartzman ML, Silva JL, Lin F, Nishimura M, Abraham NG. Cytochrome P4504A expression and arachidonic $\omega$-hydroxylation in the kidney of the spontaneously hypertensive rat. Nephron. 1996;73:652-63.

99. Humbert M, Sitbon O, Simonneau G. Treatment of pulmonary arterial hypertension. N Engl J Med. 2004;351:1425-36.

100. Taylor BJ, Mojica CR, Olson TP, Woods PR, Frantz RP, Johnson BD. A possible role for systemic hypoxia in the reactive component of pulmonary hypertension in heart failure. J Card Fail. 2013;19:50-9.

101. Ichihashi M, Ueda M, Budiyanto A, Bito T, Oka M, Fukunaga M, et al. UVinduced skin damage. Toxicology. 2003;189:21-39.

102. Oliver PL, Finelli MJ, Edwards B, Bitoun E, Butts DL, Becker EBE, et al. Oxr is essential for protection against oxidative stress-induced neurodegeneration. Plos Genetics. 2011;7:e1002338.

103. Kim J, Pajarillo E, Rizor A, Son DS, Lee J, Aschner M, et al. LRRK2 kinase plays a critical role in manganese-induced inflammation and apoptosis in microglia. PLoS ONE. 2019;14:e0210248.

104. Qiu Q, Zhang GJ, Ma T, Qian WB, Wang JY, Ye ZQ, et al. The yak genome and adaptation to life at high altitude. Nat Genet. 2012;44:946-9.

105. Guo XQ, Chen FZ, Gao F, Li L, Liu K, You LJ, et al. CNSA: a data repository for archiving omics data. Database (Oxford). 2020; 2020: baaa055.

106. Chen FZ, You LJ, Yang F, et al. CNGBdb: China National GeneBank DataBase. Hereditas. 2020;42:799-809.

\section{Publisher's Note}

Springer Nature remains neutral with regard to jurisdictional claims in published maps and institutional affiliations. 